\title{
9 \\ Genetic, biochemical and medicinal resources \\ how much can we own, protect and receive credit for?
}

\section{Lohi Matainaho}

Papua New Guinea has for many years been a site and focus of many social and scientific research activities carried out by academic and research institutions both from within its borders and from overseas. The country has been a target for these activities because of its diverse assembly of language, people and environment. It is generally acknowledged that the population of Papua New Guinea is the most culturally diverse in the world and that it has a highly diverse biological environment. Such diversity and the interaction of people with the natural environment in an island country for many thousands of years has provided a rich resource base for genetic, biochemical and medicinal research discoveries.

In the last 10-15 years there has been an unprecedented interest in bioprospecting in Papua New Guinea, as there has been in other developing countries. Prospectors look for human, animal, plant and soil-derived genetic and biochemical material that may be of commercial value. The scrutiny of biological diversity, guided by traditional knowledge regarding diseases and treatments, has led to useful ethnobotanical information that may be important in discovering bioactive compounds for pharmaceutical and agricultural purposes.

Screening tests on plant material derived from traditional knowledge tend to yield a higher percentage of positive results compared with screening on the basis of random collections (Cox and Balick 1994). Traditional medicinal knowledge has therefore made easier the 
identification of useful compounds. Papua New Guinea has now become a target of drug research by many institutions from developed countries.

\section{Genetic and biochemical resources}

Many research studies in Papua New Guinea have revealed biological characteristics unique to its people, and have therefore provided useful information about their behaviour and survival, as well as the biochemical characteristics and profiles of diseases. Studies have also shown the occurrence of certain diseases or strains of viruses and parasites amongst population groups which illustrate geographical pooling or clustering. This provides evidence of inherent mutations and of the process of coevolution (Katz and Skalka 1990; Doolittle et al. 1989).

Pioneering research carried out by Carlton Gajdusek and coworkers from the 1950s to the 1970s on the Fore people of the Eastern Highlands led to the discovery of a variant form of Creutzfeldt-Jacob Disease, commonly known as kuru (Zigas and Gajdusek 1957; Alpers and Gajdusek 1965). Gajdusek later received a Nobel Prize for this work. More recently a discovery was made of a variant human T-cell lymphoma/leukemia virus type I (HTLV-I) among the Hagahai people (Yanagihara et al. 1990; Yanagihara et al. 1991). This finding resulted in the patenting by United States scientists of a human cell line derived from the blood of a Hagahai man. Discoveries like these, made from human blood, support and complement the functions of the Human Genomic Diversity Project. The project is aimed at collecting blood, especially from isolated and less known populations, in an attempt to discover gene sequences that may be useful in gene therapy. Geographical and ethnic confinement of critical data have therefore been a strong base for scientific reasoning and explanation for disease patterns, transmission and variation (or evolution). In the area of malaria research there are current efforts to trial antigens, some presumably derived from Papua New Guinea sources, as possible vaccine candidates for the disease.

There is no doubt that medical discoveries originating from Papua New Guinea have led to the elucidation of the molecular mechanisms of disease and consequently the development of appropriate strategies for the control and treatment of specific and related diseases. Unfortunately, many such discoveries and their potential applications - which have been conveyed in scientific journals and international meetings-have been credited almost entirely to the scientists involved and their grant donors, without any credit to the source of the original material. 


\section{Traditional knowledge as a medical resource}

Traditional knowledge regarding diseases and their treatment has been part of the evolving cultures of many communities in Papua New Guinea. This knowledge is passed from generation to generation. Societies in Papua New Guinea are rich in knowledge about the use of plant and animal material for treating illnesses (Holdsworth 1977).

Surveys of medical practices and traditional uses of plants over the last 100 years have documented some of this knowledge (Hill 1985). However, traditional understanding regarding the aetiology of diseases, their diagnosis and treatment is generally viewed by Western medicine as having no scientific basis. Scientific-based principles regarding proper diagnosis of diseases and knowledge about the efficacy and toxicity of plant drugs is lacking. Despite that, there has been much anecdotal support for traditional therapies using plant preparations. Indeed, many clinically useful drugs such as vincristine (anti-tumor), morphine (analgesic), codeine (antitussive/analgesis), quinine and artemisinin (anti-malaria) are derived from medicinal plants. But, even with such a contribution, medicinal plant preparations must still be subjected to rigorous scientific testing to ascertain their safety and make known the active components (Wesche 1987).

\section{Natural products and drug discovery: an example}

Interest in natural product screening and development has been expressed and planned by local individuals and institutions such as the University of Papua New Guinea and the Papua New Guinea University of Technology in collaboration with other organisations. Previous and current practice has been to accept or invite international scientists, who invariably have connections with major drug companies, to come and take plant and marine samples for intensive drug screening. Questions pertaining to credit or compensation to the resource owners and owners of the knowledge have rarely been addressed. In the event that a major drug discovery is made, whether directly or indirectly, from the crude material from Papua New Guinea, it is possible that Papua New Guinea would never know about it. This may mean that any significance of that discovery to traditional knowledge is also lost.

A project to develop drug discovery programs using Papua New Guinea plants is being prepared jointly by researchers from the University of Papua New Guinea, the University of Utah and the United States National Cancer Institute. The arrangement includes three months of training for the author 
at the United States National Cancer Institute. The training will involve techniques using various cancer cell lines, including a non-infectious strain of human immunodeficiency virus (HIV).

Another investigator, Dr Todd Capson of the University of Utah, has been conducting ethnobotanical surveys on the uses of plants by the people in the Lakekamu Basin in the Gulf Province and the Crater Mountain area of the Eastern Highland Province. Recording of knowledge is based on people's willingness to share and to safeguard valuable information before the people who have that information die. Dr Capson's work in these areas is being carried out in collaboration with the Foundation of the Peoples of the South Pacific/Papua New Guinea, Inc. and the Research and Conservation Foundation of Papua New Guinea respectively (Capson forthcoming). It is hoped that the University of Technology, the Papua New Guinea Institute of Medical Research and other institutions may become involved.

The project is also intimately concerned with the protection and conservation of the natural flora and fauna and the promotion of sustainable use with a low or no destructive impact-but with maximum benefits for the community. For example, the discovery of a drug would mean improvement of health and lifestyle and the protection, preservation or cultivation of the plant, not to mention the economic benefits. Research efforts will no doubt be coordinated with Papua New Guinea-based conservation organisations.

\section{Agreement for drug discovery}

Before any work on the drug discovery project begins, a detailed agreement between the resource owners and the participating institutions in Papua New Guinea and the United States will have to be developed and signed. It is proposed to involve Conservation International, a major international non-government organisation, in the preparation of the agreement.

The basis of the agreement is to give equitable recognition or compensation to the people for the knowledge and resources they own (as original owners), and to realise their role in the development of a natural product. Contractual arrangements will include

- authorisation for access and collection of materials

- transfer agreements between institutions

- sharing of royalties and rights to ownership of discoveries.

Long-term benefits for the country include the development of scientific infrastructure and human resources. Research and development will be an 
integral part of the project. The agreement will no doubt maintain some degree of flexibility to enable those involved to explore carefully the extent of traditional ownership and transparency in the project.

\section{How much can we own, protect and receive credit for?}

Issues of ownership and access to genetic material in developing countries have generated much discussion in recent years and played an important part in the discussions that led to the signing of the Convention on Biological Diversity in Rio de Janeiro in 1992. The Convention recognises the ownership of biodiversity by sovereign countries and calls for equitable economic sharing arrangements between resource owners and users. However, it fails to make clear a provision for human genetic resources.

Underpinning the issue of ownership is the inherent value of the material, commodity or knowledge to the people concerned. In traditional Papua New Guinea societies, a value cannot be determined absolutely. Instead, values are relative and equal to exercising one's right and privileges to something before someone else. Relationships in this context are fundamental components. The value of the object per se is not necessarily the critical issue of contention. Equally important could be simply respecting the perspective that 'it is not an issue of money; it's one of respect for our ideas in creating knowledge that will help people'-as was recently argued by a leading scientist who was left out in a patent (Nowak 1995:899).

Ironically, it may take an outsider to recognise the relevance and value of plant or human genetic material and knowledge (for example, ethnobotanical information) to the wider community. Value in this case may assume a different contextual meaning. In general, value or relevance to other people is perceived easily, but value for commercial purposes inserts a new dimension into what may not have been the original purpose-although the use-purpose is generally acknowledged. This new purpose or perspective brings in the concept of added value. If this can be equated to value added to a commodity, then a tax-royalty compensation can be considered, similar to the concept of value added tax. This taxroyalty compensation would be relative and depend on the added value of the new or modified product.

Ownership and value in traditional communities mean status and respect, as, for example, in being a leader. Such a position in the community can be compromised if valuable knowledge is disseminated or 
lost to other people. Protection of possessions, whether they are materials or knowledge regarding an art or skill, must therefore be guarded jealously. But, as with other systems, circumstances can change. Given the variability that exists amongst villages, the rules regarding ownership can be stretched. Such dynamism in the traditional realm also assumes that the principles governing ownership in communities or villages in Papua New Guinea are similar but with boundaries that vary greatly. For example, flexibility in allowing cultural material or information to be shared may differ amongst groups.

These observations provide some guiding principles (though are not exhaustive, by any means). On the basis of these, it is possible to observe that the answer to the question of how much can we own, protect and receive credit for must reflect the following important considerations

- ownership of the original material and knowledge

- value attached to helping other people

- commercial value

- value added by modification and development.

'Original material and knowledge' acknowledges the fact that there is a source or proprietor, and value attached to an idea or thing. This implies ownership and an already existing relationship between the owner and the material or the knowledge. Such a relationship may be typically equated to an inherent value, which at the village level (that is, the level of original use) is absolute or 100 per cent of the value of the material of knowledge.

'Helping other people' acknowledges that people other than the original owner are sharing and benefiting from the traditionally derived material and knowledge. The new users may include those in the same village, outside communities or even scientists. This level is generally noncommercial, and as such is normally based on trust and confidentiality. The inherent value is intact only as far as the original use and purpose is exercised or implied in full. Full credit is therefore due to the resource owners. But in the event of a new use or potential being uncovered, this will lead to a new value being introduced, and will therefore reduce the inherent value (that which is related to the original use or purpose). In principle the inherent value becomes relative to the exercise of the new use. In this respect, some acknowledgment or credit to the resource owner would generally be appropriate.

'Commercial value' acknowledges that there are other values and interests attached to an idea or thing. The original use or the new use may become commercially valuable. An appropriate determination can therefore be 
made based on the principles stated above. In this situation, acknowledgment or credit should follow the manner of the interest being expressed along commercial lines. The inherent value, if it can be determined, may assume the character of a tax-royalty compensation where it is dependent on the new value being added.

'Modification and development' acknowledges the input of others to derive something new-with a new value attached. This level is generally the same as commercial value but recognises the novelty of the material or product being developed from what was derived from the resource owners. The original source of the material is generally not recognisable or visible.

Novelty can shift much of the credit or benefits to the discoverer with little or nothing going to the resource owners. For this reason, the issue of inherent value can be difficult to determine other than in the context of being the source of the new product. In addition, the novel product may also assume its own inherent value which may decrease the value that should go to the resource owners.

Despite this difficulty, the value accorded to the resource owners can be made more tangible by involving the resource owners as partners in the development of novel products using their resources. Although their involvement may not be visible in the laboratory, there can be clear transparency as to their involvement up to the final stage of product development. In this way, resource owners can continue to exercise some ownership over the products that are being developed from their traditional base.

A careful analysis and consideration of these issues can ensure that people receive a fair share of what was originally derived from them. One should keep the big picture in mind. Under the model proposed here, resource owners would be partners with scientists (and other interest groups) in developing plant-derived medicines for commercial and health use to benefit them and all humankind. The greater involvement of people in such enterprises can only maximise what they can own, protect and receive credit for. 